\title{
In vitro Corrosion and Haemocompatibility of Bulk Nanocrystalline 304 Stainless Steel by Severe Rolling
}

\author{
Feilong $\mathrm{Nie}^{1, \mathrm{a}}$, Yanbo Wang ${ }^{1, \mathrm{~b}}$, Shicheng $\mathrm{Wei}^{2, \mathrm{c}}$, Yufeng Zheng ${ }^{1,2, \mathrm{~d}^{*}}$ and \\ Shenggang Wang ${ }^{3, e}$
} ${ }^{1}$ State Key Laboratory for Turbulence and Complex System and Department of Advanced Materials
and Nanotechnology, College of Engineering, Peking University, Beijing 100871, China

${ }^{2}$ Center for Biomedical Materials and Tissue Engineering, Academy for Advanced Interdisciplinary Studies, Peking University, Beijing 100871, China

${ }^{3}$ Shenyang National Laboratory for Materials Science, Institute of Metal Research, and International Centre for Materials Physics, Chinese Academy of Science, 72 Wenhua Road, Shenyang 110016, China

\author{
aniefeilong@pku.edu.cn, byanbo.pku@pku.edu.cn, 'weishicheng99@163.com, \\ dyfzheng@pku.edu.cn, esgwang@imr.ac.cn
}

Keywords: nanocrystalline 304ss; electrochemical corrosion; ion release; cellular morphology; haemocompatibility.

\begin{abstract}
Bulk nanocrystalline 304 stainless steel (nanocrystalline 304ss) discs had been successfully prepared by the commercial microcrystalline 304 stainless steel (microcrystalline 304ss) plate using severe rolling technique. Micro-hardness was measured to reveal the different mechanical behavior after the severe plastic deformation. The electrochemical corrosion resistance and ion release behavior after immersion of the samples were investigated in Hank's solution for its potential use as implant and orthodontic appliance in body. Furthermore, murine fibroblast cells were indirectly employed to detect cytotoxicity by co-incubation with the extraction from the given materials. Haemocompatibility, consisting of hemolysis test and adhesion of the platelets, was also measured with fresh human whole blood and platelet-rich plasma respectively. Polarization resistance trials indicate that nanocrystalline 304ss is more corrosion resistant in the Hank's solution, with lower current density and superficial corrosion morphologies. The release values of the biotoxic ions after immersion do not exceed the set limit and turn to be well below the critical value necessary to induce allergy and below daily dietary intake level. Cellular interaction is observed via the proliferated feature of the cell line. Hemolysis and platelet adhesion results elucidates that nanocrystalline 304ss is biological and hematologic compatible.
\end{abstract}

\section{Introduction}

Conventional polycrystalline SUS 304 stainless steel (generally with the grain size at micrometer scale) is one type of austenite steel that has face-centered cubic (FCC) lattice structure without magnetism. It has been well used in biomedical areas typically as surgical implant [1], cardiac peacemaker electrodes [2], dental fixation as plates or screws [3] and orthodontic archwires or brackets [4] due to its well-behaved corrosion resistance, excellent mechanical performance, favorable bio-affinity, as well as good machinability and low cost.

Although traditional microcrystalline 304ss implants provide better biomechanical properties than other biomedical metals such as cobalt chromium alloys, titanium [5], localized corrosion of microcrystalline 304ss implants like pitting or stress corrosion were recently reported within the environment of the human body [6,7]. Even in particular cases, some metallic ions from traditional microcrystalline 304ss dissolved out and lead toxic or side effects around [8]. In addition, 
unsatisfactory cyclic strain and stress fatigue [9] and wear [4] characteristics have been other limits of its wider usage.

Bulk nanostructured metal-materials, typically nanocrystalline Ti alloys, are highlighted to be the next generation biomaterials [10] for their unique manifestation such as physical [11], electrochemical [12] and biocompatible properties [13].

In this paper, nanocrystalline 304ss sheet has been fabricated from conventional microcrystalline 304ss plate by deep rolling treatment [14]. The bio-corrosion and ion release behavior in simulated body fluids, cellular responses and haemocompatibility of nanocrystalline 304ss were studied in the present study, with the microcrystalline 304 ss as control.

\section{Materials and methods}

\subsection{Materials preparation}

The nanocrystalline 304 stainless steel (denoted as nanocrystalline 304ss) sheet was fabricated from the commercial microcrystalline 304 stainless steel (denoted as microcrystalline 304ss with stoichiometric composition referenced by ASTM A240 [15]) by severe rolling technique.

All the samples were cut into square $\left(10 \times 10 \times 1.5 \mathrm{~mm}^{3}\right)$ for corrosion, cytotoxicity and hemolysis tests. Each sample was mechanically polished up to 2000 grit, ultrasonically cleaned by acetone, absolute ethanol and distilled water in sequence, and then dried in open air. For cytotoxicity tests, samples were sterilized by autoclave for about 40 minutes. Micro-hardness on the sample surface was measured by HMV-2T (SHIMADZU, Japan), with load of $50 \mathrm{~g}$ and holding time of $10 \mathrm{~s}$.

\subsection{Electrochemical measurement}

A three-electrode cell was used for electrochemical measurements. The counterelectrode was made of platinum and the reference electrode was saturated calomel electrode (SCE). The exposed area of the working electrode (microcrystalline 304ss and nanocrystalline $304 \mathrm{ss}$ ) to the solution was $0.2826 \mathrm{~cm}^{2}$. All the measurements were carried out on an electrochemical workstation (CHI660C, China) at the temperature of $37^{\circ} \mathrm{C}$ in Hank's solution. Morphological observation on the corrosive surface was carried out by environmental scanning electron microscopy (ESEM, AMRAY-1910FE).

\subsection{Immersion test}

The immersion test was performed according to ASTM-G31-72 [16]. Experimental samples $\left(10 \times 10 \times 2 \mathrm{~mm}^{3}\right)$ were immersed in $50 \mathrm{ml}$ solutions and the temperature was kept at $37^{\circ} \mathrm{C}$ by water bath. At the very different time-point as designed, part of immersion solution by several milliliters was collected and kept under $4^{\circ} \mathrm{C}$. The inductively coupled plasma atomic emission spectrometry (Leeman, Profile ICP-AES) was employed to measure the concentrations of $\mathrm{Fe}, \mathrm{Cr}$, Ni element ions which might have dissolved from the alloy samples. An average of three measurements was taken for each group.

\subsection{Cytotoxicity test}

Murine fibroblast cells (L-929 and NIH 3T3) were adopted to evaluate the cytotoxicity of the samples. The cells were cultured in Dulbecco's modified Eagle's medium (DMEM), 10\% fetal bovine serum (FBS), $100 \mathrm{U} \mathrm{ml}^{-1}$ penicillin and $100 \mu \mathrm{g} \mathrm{ml}^{-1}$ streptomycin at $37^{\circ} \mathrm{C}$ in a humidified atmosphere of $5 \%$ $\mathrm{CO}_{2}$. The cytotoxicity tests were carried out by indirect contact. The culture and seeding details were specifically described in our previous work [17]. The spectrophotometrical absorbance of the samples was measured by microplate reader (Bio-RAD680) at $570 \mathrm{~nm}$ with a reference wavelength of $630 \mathrm{~nm}$. Optical Microscope (Olympus $1 \times 71$, Japan) was used to observe the morphology of cells.

\subsection{Hemolysis test and platelet adhesion}

Healthy human blood from a volunteer containing sodium citrate (3.8 wt.\%) in the ratio of 9:1 was taken and diluted with normal saline (4:5 ratio by volume). Normal saline solution was used as a negative control and deionized water as a positive control. In addition, the hemolysis was calculated using an ultraviolet spectrophotometer at $545 \mathrm{~nm}$ (UNIC-7200, China). The Platelet-rich plasma was overlaid atop the experimental alloys plates and incubated at $37^{\circ} \mathrm{C}$ for $1 \mathrm{~h}$. The adhered platelets were fixed in $2.5 \%$ glutaraldehyde solutions for $1 \mathrm{~h}$ at room temperature followed by dehydration in a 
gradient ethanol for $10 \mathrm{~min}$ each and dried in hexamethyldisilazane (HMDS) solution [18]. The surface of platelet attached experimental alloy plates were observed by ESEM. Different fields were randomly counted and values were expressed as the average number of adhered platelets per $\mathrm{mm}^{2}$ of surface.

\section{Results and discussion}

The phase structures and grain size of the nanocrystalline 304ss had been reported in our previous work [19-21], in which the grain size of the experimental sample was found to be remarkably reduced from micro-scale (about $100 \mu \mathrm{m}$ ) to nano-scale(about $50 \mathrm{~nm}$ ) by the XRD patterns, Scherrer calculation and TEM. Fig. 1 shows the results of $\mathrm{HV}$ and equivalent $\mathrm{HRC}$ values of microcrystalline 304 ss and nanocrystalline 304 ss respectively (293.8 \pm 11.9 vs. $480.0 \pm 10.1$ for $\mathrm{HV}$ and $28.9 \pm 1.6$ vs. 47.6 \pm 0.7 for HRC). An elevated level of hardness for the group of nanocrystalline $304 \mathrm{ss}$ mightt be contributed to their defect-free structure, the increased grain boundaries and enhanced free energy for breakage due to the refinement of nanostructure, as mentioned in the reference [22].

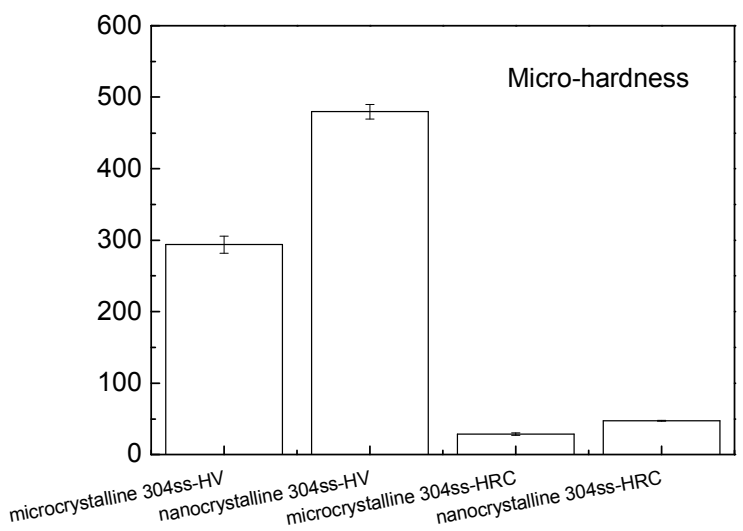

Fig. 1 Micro-hardness of microcrystalline 304ss and nanocrystalline 304ss

Fig.2(a) shows that the OCP curves of nanocrystalline 304ss and microcrystalline 304ss in Hanks' solution, which are almost in superposition, with the sudden initial potential of about $-0.07 \mathrm{~V}$ and $-0.10 \mathrm{~V}$. After quickly reaching the peak value, the OCP decreases slightly with the further increment of time. This means that quickly-formed passive film on top of the sample surface keeps attenuating till the end, which also reveals that the alloy surface is not thermodynamically stable to some extent. Fig.2(b) shows the potentiodynamic polarization curves of microcrystalline 304 ss and nanocrystalline 304 ss in Hank's solution. All the polarization curves indicate the typical feature of the active-passive-transpassive-active procedure. Compared to that of microcrystalline $304 \mathrm{ss}$, the curves of nanocrystalline $304 \mathrm{ss}$ are shifted towards the left upper side, which implies better corrosion resistance with lower current $\left(i_{\text {corr }}=7.8 \times 10^{-5} \mathrm{~A} / \mathrm{cm}^{2}\right.$ vs. $\left.2.6 \times 10^{-4} \mathrm{~A} / \mathrm{cm}^{2}\right)$ and little higher potential $\left(E_{\text {corr }}=-0.265 \mathrm{~V}\right.$ vs. $-0.273 \mathrm{~V}$, for nanocrystalline $304 \mathrm{ss}$ and microcrystalline $\left.304 \mathrm{ss}\right)$. Moreover, in the presence of the chloride ion, the passive layer becomes unstable above the breakdown potential $\mathrm{E}_{\mathrm{bd}}$, (a parameter to characterize the pitting behavior defined by ASTM [23]). The discrepancy for $\mathrm{E}_{\mathrm{bd}}$ between nanocrystalline $304 \mathrm{ss}(0.65 \mathrm{~V})$ and microcrystalline $304 \mathrm{ss}(0.80 \mathrm{~V})$ in Fig. $4(\mathrm{a})$ is not so big-gapped, which means that there is no superior resistance to pitting corrosion for nanocrystalline 304 ss. The range of so-called immunity zone between "the corrosion potential" $\left(\mathrm{E}_{\mathrm{i}}=0\right)$ and the breakdown potential represents weak or even insignificant corrosion. As far as samples in Hank's are concerned, the current density stays low within the immunity zone up to $0.85 \mathrm{~V}$-approaching that of precious metals (about $0.9 \mathrm{~V}$ ), which reflects a well-behaved corrosion resistance for both experimental samples in the chloride environment. Fig. 3 shows the SEM image of the experimental alloy samples with pits etching after polarization test up to $1.2 \mathrm{~V}$. Compared with the bigger holes and 
remarkable corrosion edge on the surface of microcrystalline 304ss, more dimple-like shallow dots were seen beneath the general pitting on surface of the nanocrystalline 304ss in Hank's solution. This may be explained by the reason that pitting corrosion are more susceptible to occur and propagate at the areas of macroscopic defects and around grain boundaries, then nanocrystalline 304 ss with ultrafine grains, resulting from the severe plastic deformation, would suffer more severe pit corrosion.
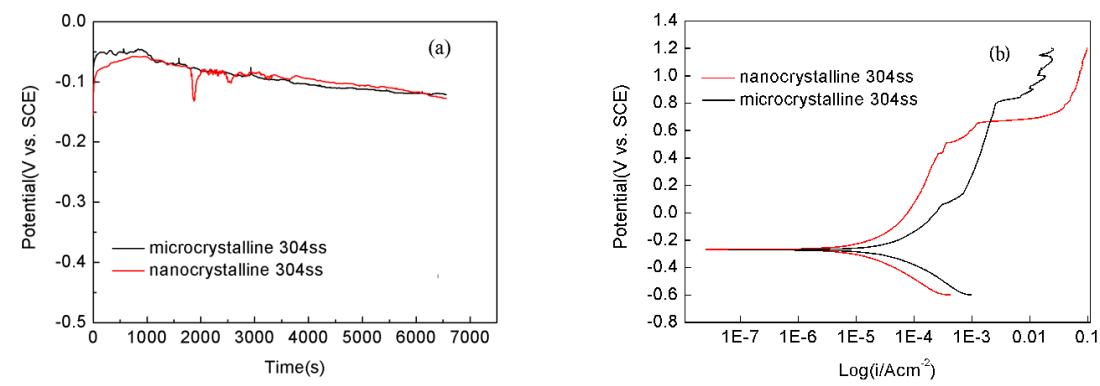

Fig. 2 The electrochemical curves of a) OCP and b) polarization of microcrystalline 304ss and nanocrystalline 304 ss
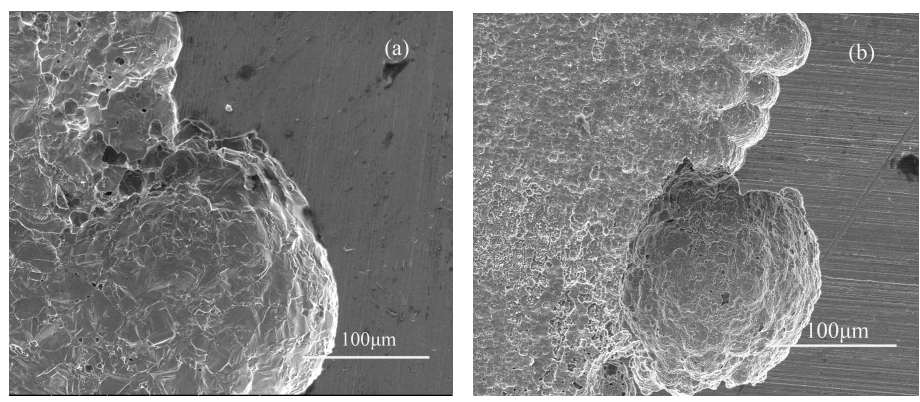

Fig. 3 SEM images of corrosive surface on a) microcrystalline 304ss and b) nanocrystalline 304ss

Many alloying elements like $\mathrm{Cr}, \mathrm{Ni}, \mathrm{Mn}$ and $\mathrm{Si}$ are incorporated into 304ss as part of ingredient to improve the corrosion resistance and stabilize the austenite phase. However, metal ions such as chromium and nickel are cytotoxic, and even iron ion has minimal adverse effect [24]. Thus, the metal ion leakage into the body internal environment from implantation materials must be highly estimated and accurately inspected. Fig. 4 reveals the overall released concentrations of $\mathrm{Ni}^{2+}, \mathrm{Fe}^{3+}$ and $\mathrm{Cr}^{6+}$ till 63 days immersion detected by ICP-AES for the present materials. It's easily seen that in Hank's solution, the release of $\mathrm{Cr}$ ion can be divided into threestages during the measurement. Within each interval, the concentration of $\mathrm{Cr}$ ion declines down clearly to the minimum gradually and the $\mathrm{Cr}$ ion released from nanocrystalline $304 \mathrm{ss}$ is higher than that from microcrystalline $304 \mathrm{ss}$. As for Ni ion, an initial burst of peak exists from the nanocrystalline 304ss on the first day, then it goes down. Another release jump occurs on the 2-week timepoint from both microcrystalline 304ss and nanocrystalline 304 ss. Similar tendency about the ion release has also been reported $[25,26]$. The concentration of Fe ion release is not shown here because it is far below the detection limit of the ICP-AES equipment. No excess of ions over the critical threshold of $2.9 \mathrm{~g} / \mathrm{ml}$ for $\mathrm{Ni}, 0.9 \mathrm{~g} / \mathrm{ml}$ for $\mathrm{Cr}$ and $20 \mathrm{~g} / \mathrm{ml}$ for Fe to cause the cytotoxicity [27] was detected in the present study. Even the release rate of $\mathrm{Ni}$ and $\mathrm{Cr}$ are far below the limit of $0.2 \mu \mathrm{g} /\left(\mathrm{cm}^{2}\right.$ week $)$ set by European Directive [28].

Murine fibroblast cells like L-929 and NIH 3T3 were co-cultured together with the extractions to evaluate the cytotoxicity in vitro. The variation tendency of the cell viability with culture time for nanocrystalline $304 \mathrm{ss}$ and microcrystalline 304 ss groups is similar, i.e., for extracts from both samples cultured with fibroblast cells, the proliferation decreased slightly with the increase of culture time, especially for the case of L-929 cell line. For either L-929 or NIH 3 T3 cell line, the proliferation rate of microcrystalline 304ss and nanocrystalline 304ss groups stay over $100 \%$ till 4 days culture, representing as an excellent non-toxicity feature. The optical microscopic observation results of the 
cells after 4 days culture are given in Fig. 5, showing the morphology of well-attachment onto the wall of 96-well plate of cells with spindle or fusiform shape, similar to that of negative control group. While for the positive control group, the cells exhibited mostly round-shaped and are floated above the 96-well plate surface, indicating their mostly dead condition.
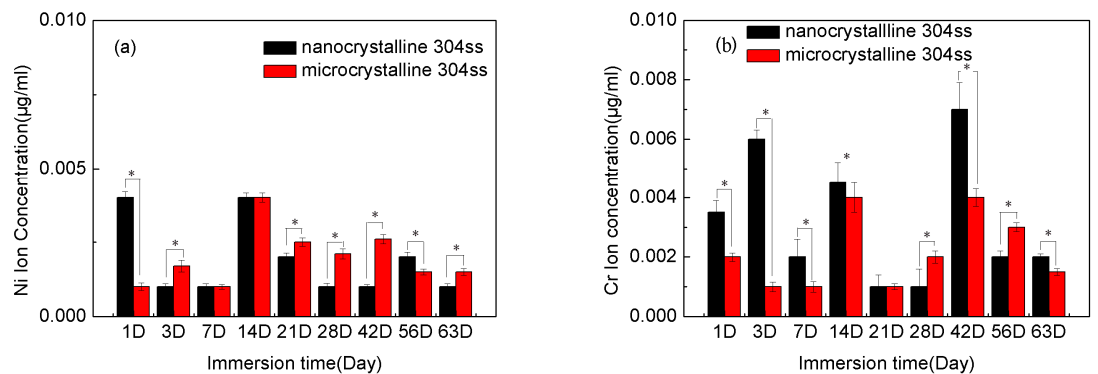

Fig. 4 Ion release after immersion of a) $\mathrm{Ni}$ and b) $\mathrm{Cr}$ from microcrystalline 304ss and nanocrystalline 304 ss

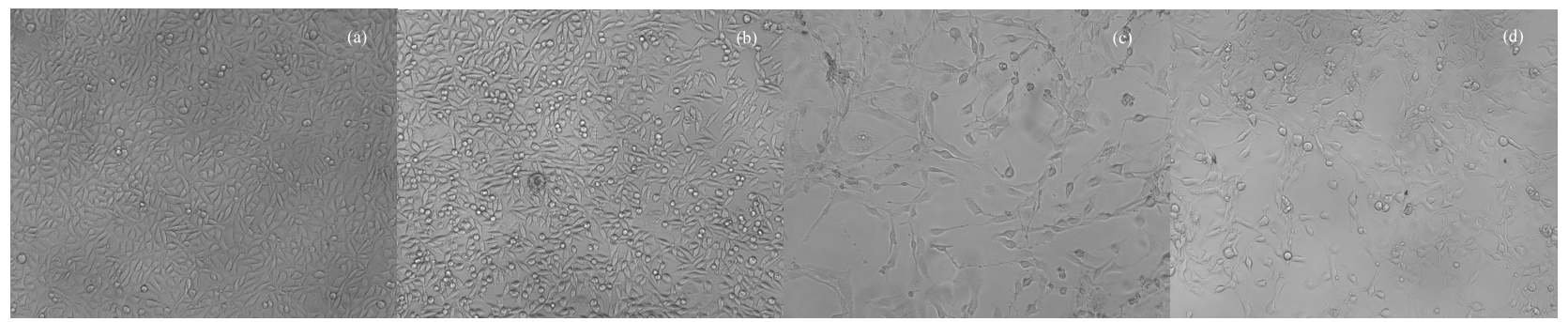

Fig. 5 Cell morphologies of L-929 under OM with a) microcrystalline 304ss and b) nanocrystalline 304ss; NIH 3 T3 with c) microcrystalline 304ss and d) nanocrystalline 304ss

When biomaterials are in direct contact with the blood, it is prone to initiate the formation of clots, as platelets and other components of the blood coagulation system are activated [8]. It is well known that the formation of thrombus is dependent upon the behavior of platelets near the implanted materials surface and the protein-based coagulation cascade. Fig. 6 shows the hemolysis percentage of fresh human blood on nanocrystalline 304ss and microcrystalline 304ss samples, $1.97 \%$ and $0.74 \%$ respectively, which are less than 5\%, a judging criterion for excellent hemolysis compatibility. The inset in Fig. 6 shows the SEM images of the platelets adhered on the sample surface respectively. It can be seen that most of the platelets present nearly small round ellipse (about 5-7 $\mu \mathrm{m}$ ) with short pseudopodia spreading on the surface of both nanocrystalline 304ss and microcrystalline 304ss samples, and very few agglomeration and distortion of platelets can be observed, implying a negative activity and good anti-platelet adhesion property. Yet the density of platelets adhered to nanocrystalline 304ss sample is much lower than that adhered on microcrystalline 304ss sample, just 214 platelets $/ \mathrm{mm}^{2}$ versus 1034 platelets $/ \mathrm{mm}^{2}$, showing less activation of platelets.

\section{Summary}

Compared to that of microcrystalline $304 \mathrm{ss}$, an improved corrosion resistance with less current density and little higher corrosion potential can be seen from nanocrystalline 304ss in the Hank's solution. From that of nanocrystalline 304ss samples under immersion detection, potentially toxic element as $\mathrm{Ni}, \mathrm{Cr}$ and $\mathrm{Fe}$ ions into simulated body fluids show well beneath the safety limits and below the threshold value that would make no threat or cause side effect to the cells or tissues. The cytotoxicity measurement indicated there is no toxic effect with fibroblast cells for nanocrystalline 304 ss extracts on the basis of standard evaluation, as the proliferation ratio of cells are above $75 \%$ till 4 days culture. Both the lower hemolysis rate and negative morphological status of the adherent platelets on the surface of the nanocrystalline 304ss, in comparison to the microcrystalline 304ss, reveal desired blood compatibility when exposed in circulatory blood homeostasis. 

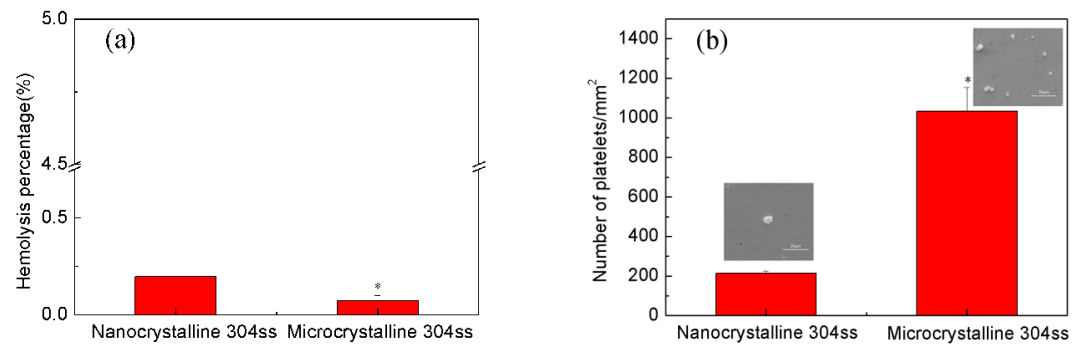

Fig. 6 Haemocompatibility evaluation of a) hemolysis rate and b) the number of platelet adhesion (SEM images as inset) of microcrystalline 304ss and nanocrystalline 304ss

\section{References}

[1] J.A. Disegi, L. Eschbach: Injury Vol. 31 (2000), p. 2

[2] S.V. Bhat: Biomaterials (Alpha Science International Ltd, Pungbourne England 2002)

[3] D.J. Blackwood and B.P.Pereira: Journal of Materials Science: Materials in Medicine Vol. 15 (2004), p. 755

[4] A. Verstrynge, J.V. Humbeeck and G. Willems: American Journal of Orthodontics and Dentofacial Orthopedics Vol. 130 (2006), p. 460

[5] H.J. Breme, V. Biehl and J.A. Helsen, in: Metals and Implants, edited by H.J. Breme, V. Biehl and J.A. Helsen, page 37 of Metals as Biomaterials, Chichester Wiley Publishers (1998)

[6] Y.C. Tang, S. Katsuma, S. Fujimoto and S. Hiromoto: Acta BiomaterialiaVol. 2 (2006), p. 709

[7] R. Nishimura and Y. Maeda: Corrosion Science Vol. 45 (2003), p. 1847

[8] Y.B. Ren, K. Yang and B.C. Zhang: Materials Letters Vol. 59 (2005), p. 1785

[9] R.W. Fuller, J.Q. Ehrgott Jr., W.F. Heard, S.D. Robert, R.D. Stinson, K. Solanki and M.F. Horstemeyer: Failure Analysis Vol. 15 (2008), p. 835

[10] T.J.Webster, in: Nanostructured Materials, edited by Ying Jackie Y, Academic Press (2001) [11] G.A. Crawford, N. Chawla, K. Das, S. Bose and A. Bandyopadhyay: Acta Biomaterialia Vol. 3 (2007), p. 359

[12] H. Gleiter: Prog. Mater. Sci. Vol. 33 (1989), p. 223

[13] D. Kshang, J. Lu, C. Yao, K.M. Haberstroh and T.J.Webster: Biomaterials Vol. 29 (2008), p. 970

[14] K. Long and S.G.Wang, China Patent ZL01128256.8. (2005)

[15] ASTM A240M-08a Annual book of ASTM standards. (Philadephia, Pennsylvania, USA 2004)

[16] ASTM-G31-72. Annual book of ASTM standards. (Philadephia, Pennsylvania, USA 2004)

[17] F.L. Nie, Y.F. Zheng, Y. Cheng, S.C. Wei and R. Z. Valiev: Materials Letters Vol. 64 (2010), p. 983

[18] X.N. Gu, Y.F. Zheng, Y. Cheng, S.P. Zhong and T.F.Xi: Biomaterials Vol. 30 (2009), p. 484

[19] N. Li, Y. Li, S.G. Wang and F.H.Wang: Electrochimica Acta Vol. 52 (2006), p. 760

[20] N. Li, Y. Li, S.G. Wang and F.H.Wang: Journal of Chinese Society for Corrosion and Protection Vol. 27 (2007), p. 80

[21] S.G. Wang, C.B. Shen, K. Long, Y. Yang, F.H. Wang and Z.D. Zhang J. Phys. Chem. B Vol. 109 (2005), p. 2499

[22] R.Z. Valiev, R.K. Islamgaliev and I.V. Alexandrov: Prog. Mater. Sci. Vol. 45 (2000), p. 103

[23] Standard terminology relating to corrosion and corrosion testing G15-07. In annual book of ASTM standard, Vol. 03, Corrosion of metals; Wear and erosion (2007)

[24] A. Doran, F.E. Law, M.J. Allen and N. Rushton: Biomaterials Vol. 19 (1998), p. 751

[25] E. Waleed, W. Ikuya and K. Mari: Dental Materials Vol. 25 (2009), p. 976

[26] K.T. Oh and K.N. Kim: Eur. J. Orthod. Vol. 27 (2005), p. 533

[27] A. Yamamoto, R. Honma and M. Sumita: Journal of biomedical materials research Vol. 39

(1998), p. 331

[28] Commission Directive2004/96/EC Official Journal of the European Union L301/51-52 (2004) 
Nanomaterials by Severe Plastic Deformation: NanoSPD5

doi:10.4028/www.scientific.net/MSF.667-669

$<i>$ In Vitro</i> Corrosion and Haemocompatibility of Bulk Nanocrystalline 304

Stainless Steel by Severe Rolling

doi:10.4028/www.scientific.net/MSF.667-669.1113 